\title{
E.А. Гончарук
}

\section{СМЫСЛ НЕВРОТИЧЕСКОГО СТРАДАНИЯ}

\begin{abstract}
Аннотация. Статья посвящена анализу мазохистского характера в творчестве американской исследовательницы К. Хорни. Рассматривая эту концепцию, автор проводит различие между пониманием мазохизма в классическом психоанализе и неофрейдизме. 3. Фрейд связывал генезис этой психологической структуры с тайной детского психосексуального развития. Однако он вовсе не сводил суть мазохизма к сексуальному феномену, как считала Хорни. В противовес Фрейду Хорни рассматривает мазохизм в социальном контексте. Его суть она усматривает в конфликте личностей. В процессе жизни люди демонстрируют разные установки - приобщение к реальности или бегство от неё, усиление личностного ядра или устранение индивидуальности. Специрику мазохизма К. Хорни усматривает в эскапизме, в устранении личностного начала. При такой трактовке снимается главный парадокс мазохистского характера - сочетание страдания и наслаждения.

В статье используются психологические методы анализа установок и механизмов. Автор прибегает также к применению методов философской антропологии. Опирается на методы неофрейдизма и учитывает в этом аспекте достижения социальной психологии. Новизна статьи в попытке целостной характеристики концепции мазохизма у К. Хорни. Впервые в отечественной литературе дается развёрнутая аналитическая оценка её взглядов. Сопоставляя фрейдистскую и неофрейдисткую трактовку мазохизма, автор обращает внимание на ошибки Хорни в оценке этого феномена.
\end{abstract}

Ключевые слова: психология, невроз, мазохизм, мазохистский характер, личность, индивидуальность, сексуальность, амбивалентность чувств, страдание, наслаждение.

Ч то нового в понимании мазохизма мы находим в работах Карен Хорни? В соответствии с общей направленностью неофрейдизма, исследовательницы пытается понять социальные корни данного явления. Она хочет осмыслить невротическое стремление к страданию психологически, не используя для этой цели биологические гипотезы.

С помощью страдания невротик достигает своих целей. Это состояние оно использует для психологического манипулирования. Страдалец, бедствующий человек вызывает жалость, готовность принять его горе и прийти на помощь. Однако за сочувствие он платит дорогою ценой. Пребывание в неврозе - это отступление от психологической нормы, погружение в такое состояние, которое оказывает разрушительное воздействие на организм. Парадоксальность мазохистского поведения обнаруживается в том, что невротик сознательно демонстрирует свою слабость. Он, погружаясь в страдание, чувствует себя счастливее.
Хорни отмечает, что эта тенденция вступает в противоречие с общими представлениями о человеческой природе. Поэтому она остается великой загадкой, камнем преткновения для психологии и психиатрии ${ }^{1}$. Само собой понятно, что это парадоксальное явление оказывается значимым не только для психологии в целом. Она привлекает внимание и философских антропологов.

Американская исследовательница показывает, что термин «мазохизм» первоначально имел отношение к сексуальным перверсиям и фантазиям. В этом случае сексуальное удовлетворение достигается путем мучений, с помощью избиений, пыток, насилования, порабощения, унижения. Фрейд тоже толковал мазохизм в русле психосексуального развития. Но Хорни отмечает, что постепенно основатель психоанализа пришёл к мысли, что эти сексуальные перверсии и фантазии совпадают с теми склонностями к страданию, которые не име-

1 Хорни Карен. Невротическая личность нашего времени. Самоанализ. М., 2004. С. 207. 
ют явной сексуальной основы. Эти тенденции он отнёс к рубрике «моральный мазохизм».

Невротик страдает добровольно. Но как провести грань между моральным мазохизмом и страданием, которое получает сексуальное удовлетворение? Хорни, прежде всего, указывает на различие в характере осознания. Когда речь идет о перверсиях и стремлению к сексуальному удовлетворению, то этот процесс и его результат осознаются. Иначе говоря, невротик понимает, что извращение дает ему половое ублаготворение. Моральный мазохизм в трактовке Хорни не имеет такой осознанности. Действие этих тенденций - и страдание и удовольствие - в значительной мере не осознается. Иначе говоря, моральный мазохизм не содержит в себе причинно-следственных связей. Невротик грызёт себя, но далеко не всегда знает, почему это происходит. Не осознается в полной мере и тот факт, что от «самогрыза» страдалец получает удовольствие. Напротив, моральный мазохист находится в состоянии печали, томления, неудовлетворенности.

Гипотезу Фрейда о мазохизме Хорни называет «яркой». Она связана с тем, что внутри человека действуют две основные биологические силы: инстинкт жизни и инстинкт смерти. Феномен мазохизма возникает тогда, когда инстинкт смерти, направленный на саморазрушение, сливается с либидозными влечениями.

Существенный вклад Хорни в трактовку самой проблемы заключается в том, что она предлагает различать само страдание и влечение к нему. Сам факт страдания и установка на него - это не одно и то же. Нет оснований смешивать искание мучений с самим процессом страдания. Хорни критикует работы известного психоаналитика Е. Дейча, который пришёл к выводу, что если в нашей культуре женщины рожают детей в муках, то значит они скрытые мазохистки. ${ }^{2}$ Они, судя, по всему, наслаждаются этими муками.

Курьёзность концепции Дейча не вызывает сомнений. Рождение ребёнка - тяжелый биологический процесс. В современной культуре многие беременные женщины заведомо соглашаются на кесарево сечение. Но это вовсе не означает, что они психологически здоровые особи. Материнство вовсе не рассчитано только на удовольствие. Избегание страданий - грозный симптом потребительского общества - тоже оказывается своеобразным невротическим состоянием. 2 Deutsch H. Motherhood and sexuality // Psychoanalytic
Quarterly. 1933. Vol. 2. P. 476-488.
По мнению Хорни, колоссальные страдания при неврозах не имеют ничего общего с желанием страдать, но представляют лишь неизбежное следствие наличных конфликтов. Иначе говоря, далеко не каждая боль может трактоваться в плане наслаждения. В самой боли нет никакого психологического подтекста. Допустим, человек сломал руку или обжёг плечо. Он испытывает боль, но вовсе не потому, что хотел этой боли. И никакой выгоды он тоже в этих случаях не получил. Это относится и к психологическим состояниям тоже. Скажем, некто испытывает тревогу. Это, разумеется, вид страдания, но далеко не всегда предумышленного. Здесь нет даже намека на удовольствие, если эта тревожность не окрасилась в мазохистские тона. Другой пример: человек страдает от того, что не может достичь нужной цели, потому что не обладает должными способностями, упорством, удачей. Он страдает, но такое происходит со многими людьми и вовсе не обязательной любой вид страдания квалифицировать как мазохизм.

Сергей Есенин написал такие строчки: «Вечером синим, вечером лунным, был я когда-то красивым и юным». Есть ли основания это печальное воспоминание об ушедшей юности трактовать как мазохизм, как тайное стремление получить удовольствие от душевной раны? Хорни справедливо предлагает исключить эти примеры из темы мазохизма. Но что же является критерием для различения страдания как такового и феномена мазохизма? На первый взгляд, таким критерием может служить тот факт, что невротик страдает больше, чем это оправдано реальностью. Можно предположить, что невротик жадно хватается за каждую возможность страдать, причем даже благоприятные обстоятельства он может обратить в нечто болезненное. Он, по словам Хорни, абсолютно не желает отказываться от страданий ${ }^{3}$.

Чтобы разобраться в сути феномена, Хорни предлагает принять во внимание те функции, которые выполняет страдание в жизни людей. Для невротика страдание имеет ценность прямой защиты от мучений. Это кажется парадоксом - спасти себя от мучений, обрекая себя на страдание. Но для невротика это единственный способ защитить себя от грозящей опасности. Если в такую ситуацию попадает обычный человек, он действует совершенно иначе, стремясь утишить боль, пре-

Хорни Карен. Невротическая личность нашего времени. Самоанализ. М., 2004. С. 208. 
одолеть ее, избежать ее глубины. Но невротик отвергает такой путь. Он идет навстречу страданию, начинает открыто бичевать себя. Таким образом, он как бы отбирает эту функцию у окружающих. Стоит ли стыдить человека за его поступок, если он сам, громче всех, осуждает себя? Позиционируя себя в качестве больного, несведущего, слабого, он избегает упреков. Принижая себя, он избегает соперничества. Да, это откровенное страдание, но в то же время и форма защиты.

Таким образом, Хорни указывает на парадоксальность мазохизма. Но ищет его корни в социальной ситуации, а не в тайне психосексуального развития, как Фрейд. Каждый из нас попадает в такой переплет, когда надо учитывать мнение окружающих. Приспособление к обстановке не всегда сопрягается с хорошо социализированным поведением. Впрочем, для мазохиста такое страдание и есть отклик на социальный вызов.

Страдание не пассивно. Оно функционально. Его назначение в том, что оно направлено на достижение собственной цели. Невротик стремится придать своим требованиям законную основу. Допустим, студент, не обнаруживший на экзамене должных знаний, пытается вызвать сочувствие, впадает в истерику, плачет и получает нужный результат: его пожалели, ушли особые обстоятельства, сделали поправку на убогость неудачника. Конечно, комиссия может раскусить банальный приемчик неуча. Но в том-то и дело, что желания невротика носят, как подчеркивает Хорни, властный и безусловный характер. Во-первых, он действительно пребывает в состоянии тревоги, а, во-вторых, погружен в собственные душевные состояния и не принимает в расчет соображения других людей.

Выходит, невротик в силу своего мазохизма имеет безоговорочные дивиденды, выходит победителем? Нет, по логике Хорни, он отнюдь не хозяин социальной ситуации. Для того чтобы отстаивать свою позицию, ему не хватает силы, ответственности, опоры на самого себя. Его тайное намерение добиться того, чтобы не он сам, а окружающие позаботились о реализации его желаний. Он убежден в том, что они отвечают за его жизнь, за все, с ним происходит. В то же время в силу невротического состояния он чувствует, что просто так никто за него ничего не сделает. Нужно мобилизовать имеющиеся ресурсы для того, чтобы заставить других пойти ему навстречу. Поэтому функционально страдание и беспомощность на- правлены к определённой цели - заслужить признание и любовь. Он предъявляет к ситуации такие требования, которые обязательны для других людей, но не для него.

Но у страдания есть еще одна функция, на которую указывает Хорни. Оно содержит обвинения в адрес других людей.

Недостаток концепции Хорни заключается в том, что она лишает мазохизм антропологической тайны. Ей кажется, что само обращение к социальности, выделение и трактовка социальных функций исчерпывающим образом позволяет понять феномен мазохизма. Она так пишет: «Когда осознаются функции невротического страдания, данная проблема отчасти лишается своего загадочного характера, но все еще остается не полностью разрешенной» ${ }^{4}$. Остальное американская исследовательницы готова прояснить в последующих рассуждениях. Да, невротик страдает больше, чем это обусловлено его стратегической целью. Он склонен преувеличивать свое несчастье, он погружается в чувства беспомощности, горя и собственной никчемности. Но невротическая склонность бросает его в пучину несчастья окончательно.

Парадокс заключается в том, что чем значительнее формальные достижения невротика, тем больше он драматизирует положение. Он чувствует себя неудачником. Окружающие, напротив, не считают его невезучим. Он же не только не верит им, но даже теряет всякое самоуважение, что понуждает его к еще большим усилиям: его охватывает паранойя, ему нужно, чтобы все согласились с его невезением. Здесь и возникает проблема, которую хочет растолковать Хорни: почему невротик добровольно распространяет свое страдание за пределы стратегической целесообразности?

Такое избыточное страдание не имеет никаких преимуществ. Во-первых, окружающие остаются при своем мнении и не разделяют нытьё невротика. Не удается также навязать другим свою волю. В чем смысл? Хорни предполагает, что мазохист рассчитывает на признание своей уникальности. Коль скоро он добровольно соглашается с самой низкой самооценкой, это означает, что он вообще находится за пределами привычных представлений об успехе и невезении, о торжестве и печали, о полноценности и неполноценности. Эти различения перестают для него существовать. Так, предположим, нищий утрачивает всякое представление

4 Там же. С. 209. 
о богатстве, поскольку оно для него недосягаемо. Следовательно, свою никчёмность, чаще всего добровольную, можно наркотизировать. Болезненные раны утрачивают свою остроту. «Страдание может служить опиумом от боли» ${ }^{5}$.

Эти рассуждения Хорни, разумеется, не отвечают на главный вопрос: почему страдание и удовольствие могут существовать вместе, как говорится слитно. Американская исследовательница пытается прояснить это, анализируя общее отношение к жизни, которое есть у невротика. Можно ли фиксировать отсутствие жизненной силы у невротиков? Хорни пишет: «В некоторых случаях это, может быть, и так, но в целом различия в жизнеспособности среди невротиков ничуть не меньше, чем среди здоровых людей. Является ли оно простым следствием базальной тревожности? Определенно тревожность некоторым образом связана с этим ощущением, но одна лишь тревожность могла бы вызвать противоположный эффект, побуждая человека стремиться и достигать все большей силы и могущества ради собственной безопасности» ${ }^{6}$.

Вывод Хорни о том, что тревожность побуждает невротика к достижению силы и могущества, безусловно, спорен. Напротив, феноменология мазохиста свидетельствует о том, что базальная тревожность как раз и способна закрепить в психологической структуре невротика склонность к самоунижению, «самогрызу», демонстративной недооценки своих качеств и жизненных установок. Желание американской исследовательницы в полемике с Фрейдом опираться лишь на социальные факторы, на характер той социальной среды, в котором оказывается новорожденный младенец, в данном случае не помогает раскрыть мазохистские обнаружения с должной глубиной.

Хорни полагает, что суть невроза индивида данной психологической структуры состоит в бессознательном преувеличении своей слабости. Она указывает также на противоречивость поведения такого персонажа. Оказывается, столкнувшись с жизненными трудностями, он поначалу готов к уступкам, но затем отказывается от каких бы то ни было компромиссов. Действительно, психологическая структура мазохиста вязкая, неуступчивая. Известно, что психологическая структура такого невротика трудно поддается коррекции и

\footnotetext{
Там же. С. 210.

6 Там же. С. 211.
}

лечению. Он чувствует, что психотерапевт укажет ему на невротическое поведение и заранее готов согласиться с этими замечаниями. Но в этой готовности принять диагноз нет ни малейшей попытки преодолеть свой невроз. Он испытывает желание придать замечаниям психотерапевта еще большую глубину, усугубляет ситуацию и, таким образом, как бы принимает аналитика в соучастники. Недаром А.Лоуэн заметил, что терапевт пытается вытащить мазохиста из пропасти, а тот, напротив, стремится увлечь его в эту бездну.

Отвергая теорию психосексуального развития ребёнка, Хорни тем не менее не может обойтись без сексуальной темы в диагностике мазохиста. Он отмечает, что невротикам такого рода присущи фантазии, в которых имеют место случаи изощренного изнасилования, избиения, унижения, принуждения к изощренным пыткам. Еще одна особенность мазохиста - стремление обузить свое Я, растворить его в чем более значимом, обширном, неизбежном. Таким способом Я невротика избавляется от сомнений, конфликтов, болей и изоляций. Эту тенденцию Хорни связывает с экспертизой Ницше. Он называл ее освобождением от principium indivuationis. «Ницше задумался над вопросом: какое значение имеет именно у греков трагический миф и чудовищный феномен дионисийского начала? - пишет К.П. Матутите. - Философ стремился постичь истинный дух греческого искусства. Ему казалось, будто греки в полной мере ощущали трагичность чувственного бытия. Человеку нужно, думал Ницше, устремляться ввысь, в мир, который мог бы возвысить человека над страданием бытия. Следовательно, человек не может должен оставаться человеком. Ему суждено стать сверхчеловеком. Но между человеком и сверхчеловеком возможен разрыв. В таком случае вся человеческая жизнь от рождения до смерти уже не рассматривалась как единственная, она полностью обесценивалась. Ницше считал, что тяга к универсальности важнейшая характеристика человеческого бытия. Именно из этой тяги рождается сознание недостаточности лишь земной жизни. Единичная земная жизнь, писал Ницше, восстает против признания ее единственной и самодовлеющей» ${ }^{7}$.

Дионисийское начало Ницше характеризует как пассивное, эскапистское, в отличие от апологического начала, которое можно назвать актив-

\footnotetext{
Матутите К.П. Фридрих Ницше о психологии. Часть 1 //
} Психология и психотехника. 2009. № 1. С. 24. 
ным, нацеленным на преображение реальности. Не только Ницше, но и многие другие исследователи стремились в разных культурах обнаружить тягу к дионисийству. Так известный американский культуролог Рут Бенедикт писала о такого рода установках, связанных с экстатическими состояниями, и обнаруживала их в культурах, далеко отстоящих друг от друга. Таким образом, она делала вывод о том, что в данном случае можно говорить об определенном антропологическом феномене.

Экскурс Хорни в культурологию тоже весьма интересен. Она связывает принцип растворения индивидуальности с ранними фрикийскими культами. А сам термин «дионисийский» был взят из культов Дионисия в античной Греции. Американская исследовательница обращается к анализу экстатических состояний. Она пишет: «По всему миру распространены обычаи и культы, следующие тому же самому принципу: в групповой форме - в виде разгула в период праздников и в религиозном экстазе и среди отдельных людей, ищущих забвения в наркотиках. Боль также играет некоторую роль в порождении «дионисийского» состояния. В некоторых равнинных индейских племенах видения вызываются посредством поста, отсечения части телесной плоти, связывания человека в болезненной позе. В «солнечных плясках» - одной из наиболее важных церемоний равнинных индейцев - физические пытки были весьма распространенным способом вызывания экстатических переживаний» ${ }^{8}$.

Сегодня мы могли бы привести гораздо больше культурологических иллюстраций, которые свидетельствует о том, что тяга людей к страданиям не является частным случаем психоаналитической практики. Это глубинная потребность человека, которая может «сгущаться» в отдельных индивидах или находить массовость в тех или иных традициях культуры. Так называемые флагеллянты, представители христианства, полагали, что причиняя себе боль и страдания, люди приобщаются к этой религии, отмаливают свои грехи перед Богом и таким образом получают прощение после смерти. Кающиеся грешники в Нью-Мехико практиковали для этой цели колючки, битье, ношение тяжестей.

Сама же Хорни, обращаясь к современной жизни, задается вопросом: как мы можем объяснить

\footnotetext{
8 Хорни Карен. Невротическая личность нашего времени.
} Самоанализ. М., 2004. С. 213. универсальность этих стремлений? Однако американская исследовательница ищет ответ не в человеческой природе, не в антропологических констатациях. Она связывает этот феномен с культурными различиями. По ее логике получается, что массовая устремленность к болезненным переживаниям свойственна все-таки не всем культурам. В частности, ницшеанский принцип растворения индивидуальности в европейской культуре, по ее мнению, наталкивается на возвеличивание Я как доминирующую тенденцию западной культуры. По ее словам, в европейской жизни заметна здоровая устремленность, готовность в продуктивной деятельности, к утверждению личностного идеала.

По мнению Хорни, ни стремление к экстазу и растворению индивидуальности, ни возвеличивание собственной сущности нельзя расценивать как патологию. Здесь действительно у американской исследовательницы есть желание провести различие между нормой и ее искажением. Однако, по нашему мнению, Хорни далеко не всегда четко классифицирует психологические феномены. По сути дела он связывает растворение индивидуальности с таким социальным явлением, как эскапизм. Разумеется, формы эскапизма весьма различны. Они имеют свои познавательные, культурные и социальные истоки ${ }^{9}$

Однако эскапизм - уход от реальности - далеко не всегда в социальной практике выражает растворение личности. Разумеется, бродяга, покинувший свой дом и ставший человеком без очага, рискует утратить свою индивидуальность, растворить личностное ядро. Однако отождествление индивида с литературным героем, будучи, безусловно, явлением эскапизма, не всегда сопровождается утратой личности. Подражание Оводу или Татьяне Лариной далеко не всегда свидетельствует об отходе от реальности или душевном обнищании. Встать на такую точку зрения означало бы принижение огромной воспитательной роли искусства вообще.

«Эскапистское сознание, - отмечает Е.О. Труфанова, - одно из проявлений сознательной деятельности человека (включающее, однако, и бессознательные мотивы). Эскапистское сознание представляет собой такой модус функционирования сознания человека, когда фокус деятельности сознания смещается с восприятия реального мира на восприятие и переживание событий виртуаль-

\footnotetext{
9 Труфанова Е.О. Эскапизм: бегство в поисках смысла //
} Психология и психотехника. 2014. № 6. С. 597-608. 
ного, воображаемого мира. Важно отличать эскапизм от простого уходе в переживание актов и событий внутреннего мира человека, эскапистское сознание - это не просто «уход в себя», это сознательное творчество виртуального мира, который является целью «бегства» ${ }^{10}$.

Невротизм мазохистской структуры связан не просто с избеганием реального мира. Точнее, невротик испытывает тягу к уходу от жизни с помощью своеобразного «бегства в болезнь», стремлению сойти с ума или умереть. Удовлетворение, которого он ищет, несомненно, связано с ослаблением или устранением собственного индивидуального «я». В галерее невротических типажах мазохист выступает как антипод нарцисса. Для последнего, напротив, характерно раздутое «я», преувеличенное представление о себе и своих возможностях. Для мазохиста же ощущение слабости и пассивности выражает стремление к удовольствию.

Сходные процессы рассматривал и В. Райх. Он также стремился рассмотреть проблему мазохизма. Райх считал, что мазохистские тенденции не противостоят принципу удовольствия. Иначе говоря, можно получить наслаждение от собственных неудач, расстройств, невезенья и болезней. Однако Хорни не рассматривает концепцию Райха, поскольку тот толкует их на основе концепции психосексуального развития ребёнка. То, что Хорни исследует как стремление к растворению индивидуальных пределов, у Райха толкуется как стремление к оргазму.

Почему невротик редко достигает забвения и раскрепощённости? С точки зрения Хорни, ему приходится постоянно восстанавливать нарушаемое равновесие между страданием и наслаждением. В конечном итоге в большинстве случаев это носит характер компромисса, поскольку полного слияния здесь быть не может. Именно поэтому Хорни считает, что внутреннее беспокойство мазохиста находит частичное восполнение благодаря способности мазохиста переносить свои неудачи на «внешний мир», считая, что мир должен приспосабливаться к нему. Он убежден в том, что имеет право на обладание своей власти над другими. Парадокс заключается в том, что невротик, с одной стороны, декларирует свою беспомощность и слабость, но именно на этой основе выдвигает притязание на всемогущество. Он ощущает себя ничтожеством, но в то же время в силу невротической

10 Там же. С. 599. логики обижается, когда его не принимают за гения. Оба эти стремления сильны и непримиримы. Пока действует невротическая структура, невозможно никакое примирение этих двух тенденций.

«Стремление к забвению является намного более властным у невротика по сравнению с нормальным человеком, - отмечает К. Хорни, - потому что первый хочет избавиться не только от своих страхов, ограничений и чувства изоляции, которые универсальны для человеческого существования, но также и от чувства того, что он пойман в капкан неразрешимых конфликтов, и от возникающих вследствие них страданий. И его красноречивое стремление к власти и возвеличиванию собственного «я» по своей силе является гораздо большим, чем у нормального человека» ${ }^{11}$.

Нельзя не отметить, что Хорни удается значительно расширить спектр амбивалентных состояний мазохиста. Кроме парадоксального сочетания страдания и наслаждения в психологической структуре этого невротика обнаруживаются и другие несовместимые тенденции. Мазохист хочет одновременно быть всем и ничем. По житейской логике самоунижение логически никак несовместимо с претензией на всемогущество и признание. В той же мере склонность быть зависимым от других людей скрывает поразительную установку невротика на торжество над окружающими. Здесь можно было бы напомнить известную полемику Н.А. Бердяева с французским персоналистом Э. Муньё. Русский философ утверждал, что тираном может оказаться любой человек. Э. Муньё не соглашался с этой идеей. Он полагал, что к деспотизму склонны особые психологические типы, те, которые страдают властолюбием и деспотизмом. Точка зрения Н.А. Бердяева в этом смысле гораздо глубже и психологичнее. В самом деле, следуя русской пословице «В тихом озере все черти водятся», можно обнаружить элементы тиранства среди тех людей, которые как будто и не помышляют об этом. Собственная предельно заниженная оценка может обернуться готовностью властвовать над людьми. Итак, мазохисты тиранят других людей, сетуя на свою слабость.

Никчёмность невротика нередко рождает у окружающих иллюзию, будто он способен на компромиссы и уступки, у него есть готовность принести себя в жертву чему-либо или кому-либо. Одна-

11 Хорни Карен. Невротическая личность нашего времени. Самоанализ. М., 2004. С. 217. 
ко и здесь кроется парадокс поведения невротика. Да, мазохист обнаруживает как будто сильное любовное чувство. Его привязанность к другому лицу часто носит характер беспредельного преклонения, полного растворения в объекте любви.

Мазохистская любовь всегда окрашена страданием, обнаруживает прилипчивость и стойкость. Об этом более подробно напишет в последующие годы Эрих Фромм в своей книге «Искусство любить». Однако не следует полагать, будто чувства мазохиста спроецированы преимущественно на другого человека. На самом деле невротическая любовь вовсе не свидетельствует о мощи объектной либидозности. И в этом случае невротик в большей степени любит себя, а не другого человека. Эгоцентрическая поглощенность своими делами и в этом случае обнаруживает себя полностью.

Показная созидательность невротика нередко обнаруживает себя в деструктивных формах. Желание обнаружить в себе плодоносность своих чувств, мазохист на самом деле ведет себя крайне деструктивно. Он разрушает любовь. Невротик смутно ощущает, что те подземные слои его психики, которые мучают его, на самом деле обладают несомненной ценностью. Здесь мазохиста подкарауливает страх, что в процессе терапии он может утратить эти значимые компоненты. Именно это чувство препятствует осознанию неврозов. Невротику мнится, что он может сойти с ума, ибо его душу охватывают непримиримые устремления.

Хорни ставит вопрос о том, какие культурные факторы способны усилить и углубить тревожность невротика. Религия, по ее мнению, утратила свое влияние на психику людей. В постановке данного вопроса американской исследовательнице не хватает, как это ни странно, культурологической глубины. Она отвлекается от многоликости цивилизационных императивов, которые влияют на массовое поведение. М. Вебер проводил различие цивилизаций по принципу их отношения к окружающему миру. Есть цивилизации, которые исповедуют уход от мира, есть такие, которые приспосабливаются к миру или, наконец, есть цивилизации, претендующие на то, что преобразить мир $^{12}$. К первому типу цивилизаций можно отнести, скажем, буддистскую цивилизацию. Она, как

12 См. об этом: Пропасть господства. Интервью с ведущим научным сотрудником Института восточных рукописей РАН Вячеславом Рыбаковым // Литературная газета. 2014. № 25. C. 9. говорится, уход от реальности. Буддист не испытывает тревожности в связи с запросами внешнего мира. Ему непонятно, почему европейцы живут в постоянной суете, стремятся к жизненным благам и достижениям. Если характеризовать конфуцианскую цивилизацию, то ее пафос - приспособление к миру. Наконец, западно-европейская цивилизация пронизана динамизмом. Дух фаустовской цивилизации направлен на преобразование мира. Она стремится преобразовать мир. В нашей культуре, в этом Хорни права, не принято отказываться от собственных притязаний и достижений. Тот, кто пренебрегает этим велением культуры, рискует нарваться на опасность остракизма.

Хорни не склонна вслед за Фрейдом рассматривать мазохизм главным образом как сексуальный феномен. Но, к слову сказать, у основоположника психоанализа и нет такой односторонней экспертизы мазохизма. Фрейд связывает характерологию невротизма с психосексуальным развитием ребёнка. Сначала он трактовал мазохизм как одну из сторон определённой, биологически заданной стадии сексуального развития. Он называл ее анально-садистической. Позже у Фрейда возникла предположение, что эти мазохистские склонности имеют внутреннее родство с женской природой. Их назначение избыть желание быть женщиной. Поздний Фрейд пришёл к убеждению, что в мазохизме таятся саморазрушительные тенденции. Они борются с сексуальными влечениями, и функция мазохизма состоит в том, что снизить вредоносность этих сплетений. Однако ни в коем мере он не рассматривает этот вид невротизма только под углом зрения сексуальности. Характеристика мазохизма у Фрейда не сводится к оценке сексуальных перверсий, а содержит также множество сугубо психологических оттенков, форм поведения и установок.

Американская исследовательница склонна рассматривать мазохистские перверсии и фантазии в последнюю очередь. Это частный случай данного феномена. Она пишет о таком невротике: «Если его действия к отказу от себя изживаются в фантазиях или в сексуальных действиях, он, возможно, сможет избежать опасности полного самоуничтожения. Подобно «дионисийским» культам», эти мазохистские привычки дают временное забвение и раскрепощение со сравнительно небольшим риском нанести себе вред. Обычно они затрагивают всю структуру личности; иногда они 


\section{Мотивация и духовность личности}

сосредоточиваются на сексуальных действиях, тогда как другие сферы личности остаются от них сравнительно свободными» ${ }^{13}$.

Каков же общий смысл концепции мазохизма у Хорни. Прежде всего, она решительно отвергает сугубо биологическую трактовку данного феномена. Мазохизм, по ее мнению, не является ни сексуальным явлением, ни результатом биологически заданных процессов. Суть мазохизма Хорни усматривает в личностных конфликтах. Такая постановка вопроса значительно расширила диапазон рассмотрения проблемы. Включение в тему социального контекста позволила, как мы видели, расширить представление о сути этого характера и о его социальных обнаружениях. Однако рассмотрение мазохизма только в социальном контексте существенно обеднило феноменологию этого характера у Хорни. Избавление экспертизы от причудливой драматургии сексуальности по сути дела превратила эту проблему в тему социальной философии.

В итоге Хорни вообще пришла к ошибочному убеждению, что невротик не хочет страдать. Это желание также мало свойственно ему, как и обычному человеку. Но кто такой мазохист, если освободить его психологическую структуру от добровольно принятых на себя мучений? Сущностью этого характера Хорни считает отказ от своего «Я». Но эскапизм, как уже было отмечено, является широким и многоликим явлением. Он гораздо шире, нежели специфика мазохизма. Отказ от своего «Я» не является привилегией мазохистского характера. Этот признак может, напротив, демонстрировать наслаждение без всякого присутствия страдания. Скажем, тяга к гиперреальности, уход от унылой повседневности можно трактовать по-разному: и как «недозагруженность личности» и как поиск более насыщенной реальности.

\section{Список литературы:}

1. Гончарук Е.А. Мазохизм как наваждение // Психология и психотехника. 2009. № 6 (9). С. 52-59.

2. Гончарук Е.А. Соотношение страдания и вины в наследии Н.А. Бердяева // Психология и психотехника. 2014 . № 5 . C. 503-507. (DOI: 10.7256/2070-8955.2014.5.11486).

3. Гуревич П.С. Как складывается характер // Психология и психотехника. 2012. № 10. С. 4-8.

4. Гуревич П.С. Мазохизм как антропологическая загадка // Теоретический журнал «CREDO NEW». 2008. № 4 (56). С. $112-131$.

5. Гуревич П.С. Психоанализ: В 2-х тт. М.: Юрайт, 2013.

6. Гуревич П.С. Философия человека (лекции) // Личность. Культура. Общество. 2006. Т. VIII. № 1. С. $184-201$.

7. Гуревич П.С. Фрейд конечный и бесконечный // Личность. Культура. Общество. 2007. Т. IX. № 2. С. 130-145.

8. Захер-Мазох Л. Венера в мехах. Демонические женщины. М., 1993.

9. Коуэн Лин. Мазохизм: юнгианский взгляд. М., 2005.

10. Крафт-Эбинг Р. Половая психопатия, с обращением особого внимания на извращение полового чувства. М., 1996.

11. Матутите К.П. Фридрих Ницше о психологии. Часть 1 // Психология и психотехника. 2009. № 1. С. 19-24.

12. Матутите К.П. Фридрих Ницше о психологии. Часть 2 // Психология и психотехника. 2009. № 2. С. 17-25.

13. Спирова Э.М. Антропологический аспект мышления // Психология и психотехника. 2012. № 5. С. 38-49.

14. Труфанова Е.О. Эскапизм: бегство в поисках смысла // Психология и психотехника. 2014. № 6. С. 597-608.

15. Фромм Э. Душа человека. М.: АСТ, 2014.

16. Х Хорни Карен. Невротическая личность нашего времени. Самоанализ. М., 2004.

17. Эрос. Философские маргиналии проф. П.С. Гуревича. М.: «Канон +» РООИ «Реабилитация», 2014.

18. Deutsch H. Motherhood and sexuality // Psychoanalytic Quarterly. 1933. Vol. 2. P. 476-488.

\section{References (transliteration):}

1. Goncharuk E.A. Mazokhizm kak navazhdenie // Psikhologiya i psikhotekhnika. 2009. № 6 (9). S. 52-59.

2. Goncharuk E.A. Sootnoshenie stradaniya i viny v nasledii N.A. Berdyaeva // Psikhologiya i psikhotekhnika. 2014. № 5. S. 503507. (DOI: 10.7256/2070-8955.2014.5.11486).

3. Gurevich P.S. Kak skladyvaetsya kharakter // Psikhologiya i psikhotekhnika. 2012. № 10. S. 4-8.

4. Gurevich P.S. Mazokhizm kak antropologicheskaya zagadka // Teoreticheskii zhurnal «CREDO NEW». 2008. № 4 (56). S. 112131.

5. Gurevich P.S. Psikhoanaliz: V 2-kh tt. M.: Yurait, 2013.

6. Gurevich P.S. Filosofiya cheloveka (lektsii) // Lichnost'. Kul'tura. Obshchestvo. 2006. T. VIII. № 1. S. $184-201$.

13 Хорни Карен. Невротическая личность нашего времени.

Самоанализ. М., 2004. С. 218-219. 


\section{Психология и психотехника 10(73) • 2014}

7. Gurevich P.S. Freid konechnyi i beskonechnyi // Lichnost'. Kul'tura. Obshchestvo. 2007. T. IX. № 2. S. 130-145.

8. Zakher-Mazokh L. Venera v mekhakh. Demonicheskie zhenshchiny. M., 1993.

9. $\quad$ Kouen Lin. Mazokhizm: yungianskii vzglyad. M., 2005.

10. Kraft-Ebing R. Polovaya psikhopatiya, s obrashcheniem osobogo vnimaniya na izvrashchenie polovogo chuvstva. M., 1996.

11. Matutite K.P. Fridrikh Nitsshe o psikhologii. Chast’ 1 // Psikhologiya i psikhotekhnika. 2009. № 1. S. 19-24.

12. Matutite K.P. Fridrikh Nitsshe o psikhologii. Chast’ 2 // Psikhologiya i psikhotekhnika. 2009. № 2. S. 17-25.

13. Spirova E.M. Antropologicheskii aspekt myshleniya // Psikhologiya i psikhotekhnika. 2012. № 5. S. 38-49.

14. Trufanova E.O. Eskapizm: begstvo v poiskakh smysla // Psikhologiya i psikhotekhnika. 2014. № 6. S. 597-608.

15. Fromm E. Dusha cheloveka. M.: AST, 2014.

16. Khorni Karen. Nevroticheskaya lichnost' nashego vremeni. Samoanaliz. M., 2004.

17. Eros. Filosofskie marginalii prof. P.S. Gurevicha. M.: «Kanon +» ROOI «Reabilitatsiya», 2014.

18. Deutsch H. Motherhood and sexuality // Psychoanalytic Quarterly. 1933. Vol. 2. P. 476-488. 